Check for updates

Cite this: J. Mater. Chem. C, 2019 7, 12926

Received 5th March 2019, Accepted 8th May 2019

DOI: $10.1039 / c 9 t c 01244 c$

rsc.li/materials-c

\title{
Vibrationally induced color shift tuning of photoluminescence in $\mathrm{Ce}^{3+}$-doped garnet phosphors $\dagger$
}

\author{
Yuan-Chih Lin, (D) ${ }^{a}$ Paul Erhart ${ }^{\mathrm{b}}$ and Maths Karlsson (D) *a
}

\begin{abstract}
A critical challenge in the field of phosphor converted white light emitting diodes ( $p c$-WLEDs) pertains to understanding and controlling the variation of emission color with device temperature. Here we, through a combined photoluminescence (PL) and Raman spectroscopy study of the three garnet type

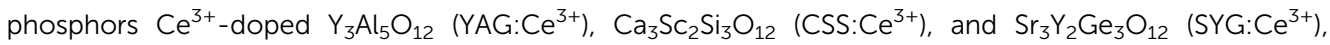
show that the color of the $\mathrm{PL}$ is systematically shifted upon changing the operation temperature of the phosphor. A general trend is observed that the $\mathrm{PL}$ exhibits a red-shift as a function of increasing temperature, until the point at which the vibrational modes of the $\mathrm{CeO}_{8}$ moieties, which induce dynamical tetragonal distortions of the $\mathrm{CeO}_{8}$ dodecahedra, are fully activated. Upon further temperature increase, the PL turns to a blue-shift because of a counteracting and predominating effect of thermal lattice expansion that progressively makes the $\mathrm{CeO}_{8}$ dodecahedra more cubal like. Since this behavior is the result of the symmetry relations intrinsic to the garnet structure, the present mechanism can be generally applicable to materials of this type. It thereby provides a route for tuning the $\mathrm{PL}$ of this important class of phosphor materials.
\end{abstract}

\section{Introduction}

The economic and environmental benefits of phosphor converted white light emitting diodes (pc-WLEDs) have been increasingly appreciated in recent years. ${ }^{1-4}$ The most widely used type of pc-WLEDs is composed of an (In, Ga,) N based blue LED that is used to excite either a yellow phosphor or a mixture of green and red phosphors, resulting in the emission of white light. ${ }^{5,6}$ Phosphors based on $\mathrm{Ce}^{3+}$-doped garnet type host lattices have garnered particular attention and are commonly used as greento-yellow component(s) in pc-WLEDs because of their high quantum efficiency and chemical stability. ${ }^{3,78}$ The garnet crystal structure, of general formula $\mathrm{A}_{3} \mathrm{~B}_{2} \mathrm{C}_{3} \mathrm{O}_{12}$, can be described by a 160-atom body-centered cubic unit cell of the $O_{\mathrm{h}}^{10}(I a \overline{3} d)$ space group. ${ }^{9}$ The structure may be also viewed as a network of $\mathrm{AO}_{8}$ dodecahedra, $\mathrm{BO}_{6}$ octahedra, and $\mathrm{CO}_{4}$ tetrahedra, which are connected to each other via $\mathrm{O}$ atoms that are shared between neighboring cation-oxygen polyhedra, see Fig. 1 . The dodecahedral coordination of A may be described as a slightly tetragonally distorted cubal environment, the tetragonality of which typically increases when A ions are substituted by $\mathrm{Ce}^{3+} .7,10,11$

\footnotetext{
${ }^{a}$ Department of Chemistry and Chemical Engineering, Chalmers University of Technology, SE-41296 Göteborg, Sweden. E-mail: maths.karlsson@chalmers.se

${ }^{b}$ Department of Physics, Chalmers University of Technology, SE-412 96 Göteborg, Sweden

$\dagger$ Electronic supplementary information (ESI) available. See DOI: 10.1039/c9tc01244c
}

Two major effects dictate the PL properties; the centroid shift and the crystal field splitting. The centroid shift refers to a lowering in the average energy of the $5 \mathrm{~d}$ levels of the $\mathrm{Ce}^{3+}$ ions due to a decrease in the interelectronic repulsion, $c f . \varepsilon_{\mathrm{c}}$ in Fig. $10^{12,13}$ This effect depends on the polarizability of the surrounding anion (oxygen) ligands and on the covalency of the chemical bonds between the ligands and the activator ion. ${ }^{12,14,15}$ The crystal field splitting refers to the splitting of the $5 \mathrm{~d}$ levels of the $\mathrm{Ce}^{3+}$ ion into an upper, triply degenerate, ${ }^{2} \mathrm{~T}_{2 \mathrm{~g}}$ state and a lower, doubly degenerate, ${ }^{2} E_{\mathrm{g}}$ state, which are separated by an energy $\Delta$ in a cubal environment, see Fig. 1. ${ }^{7,12,13,16,17}$ The ${ }^{2} \mathrm{~T}_{2 \mathrm{~g}}$ and ${ }^{2} E_{\mathrm{g}}$ states, which are degenerate for perfect cubal symmetry, are further split into five nondegenerate levels due to the tetragonal crystal field acting on the $\mathrm{Ce}^{3+}$ ion that originates from tetragonal distortions of the cubal environment of the $\mathrm{CeO}_{8}$ moiety. ${ }^{7,13}$ The strength of the tetragonal crystal field may be measured by the energy separation between the two lowest $5 \mathrm{~d}$ levels $\left(5 \mathrm{~d}_{1}\right.$ and $\left.5 \mathrm{~d}_{2}\right)$, cf. $\Delta_{12}$ in Fig. $1{ }^{13,18}$ The unusually large crystal field splitting for many $\mathrm{Ce}^{3+}$-doped garnet phosphors enables excitation in the blue wavelength region. After vibrational relaxation in the $5 \mathrm{~d}_{1}$ level, one obtains emission in the green-yellow wavelength range, which is again followed by vibrational relaxation in the uf electronic ground state. The process of the energy loss through the vibrational relaxation gives rise to the so-called Stokes shift, $c f . \Delta S$ in Fig. 1. 


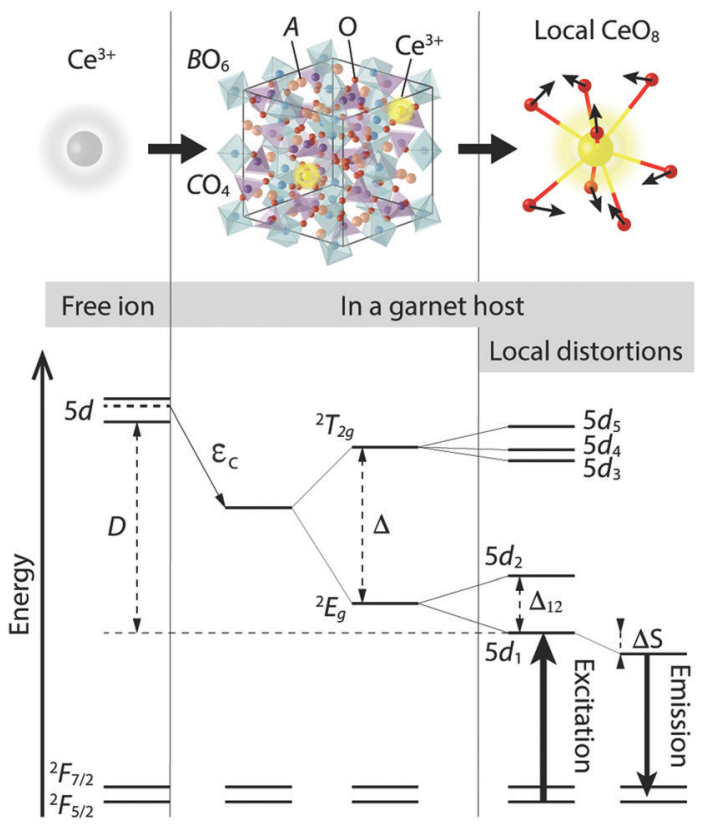

Fig. 1 Schematic illustration of the atomic environments (top) and energy level diagrams (bottom) of a free $\mathrm{Ce}^{3+}$ ion, a $\mathrm{Ce}^{3+}$-doped garnet phosphor (a unit cell), and the local coordination of $\mathrm{Ce}^{3+}$ in a garnet host.

Generally, the effect of incorporating $\mathrm{Ce}^{3+}$ ions into a host crystal is quantified by the energy difference between the lowest lying $5 \mathrm{~d}$ level of the $\mathrm{Ce}^{3+}$ ion in the free-ion state and in the host, $c f$. $\mathrm{D}$ in Fig. 1 . The $4 \mathrm{f}$ ground state of the $\mathrm{Ce}^{3+}$ ion is much less affected by the crystal field due to the shielding effect of the outer-lying filled $5 \mathrm{~s}$ and $5 \mathrm{p}$ shells of the $\mathrm{Ce}^{3+}$ ion. Rather, the $4 \mathrm{f}$ state is split into an upper ${ }^{2} \mathrm{~F}_{7 / 2}$ and a lower ${ }^{2} \mathrm{~F}_{5 / 2}$ manifold as the result of spin-orbit coupling (Fig. 1).,13,19

The sensitivity of the PL of $\mathrm{Ce}^{3+}$ to the local environment may be used for modifying the color and intensity of the emitted light. For example, cation substitution and variation of the operation temperature are common means to change the local coordination environment of the $\mathrm{Ce}^{3+}$ ions and thus for tuning PL properties. ${ }^{7,20-22}$ In particular, the degree of tetragonal distortion of the $\mathrm{Ce}^{3+}$ environment, which may be tuned by the $\mathrm{Ce}^{3+}$ concentration and/or cation co-substitution on the $\mathrm{A}, \mathrm{B}$, and/or C sites, has been shown to correlate with color shifts of the PL spectra. ${ }^{10,23-25}$ Specifically, increasing the $\mathrm{Ce}^{3+}$ concentration in the canonical green-yellow garnet phosphor $\mathrm{Ce}^{3+}$-doped $\mathrm{Y}_{3} \mathrm{Al}_{5} \mathrm{O}_{12}$ (YAG: $\mathrm{Ce}^{3+}$ ) leads to a downward-shift in frequency (red-shift) of the emitted light, as a result of increased crystal-field splitting due to enhanced tetragonal distortions of the $\mathrm{CeO}_{8}$ moieties. ${ }^{10}$ Similarly, the substitution of larger cations, such as $\mathrm{Gd}$ or $\mathrm{Tb}$, for $\mathrm{Y}$ in YAG: $\mathrm{Ce}^{3+}$ yields a red-shift of the emitted light, whereas the substitution by smaller ions such as Lu yields an upward-shift in frequency (blue-shift). ${ }^{13,26-30}$ This can be explained by the fact that the local coordination on the A sites is more tetragonally distorted when they are occupied by larger cations. Besides, complete cation substitutions (or different host compositions) have also shown to result in a strong effect on the PL properties of garnet phosphors. This may be exemplified by

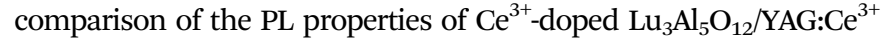
and $\mathrm{Ce}^{3+}$-doped $\mathrm{Lu}_{2} \mathrm{CaMg}_{2} \mathrm{Si}_{3} \mathrm{O}_{12} / \mathrm{Lu}_{3}(\mathrm{Al}, \mathrm{Mg})_{2}(\mathrm{Al}, \mathrm{Si})_{3} \mathrm{O}_{12}$. The replacement of $\mathrm{Al}^{3+}$ ions with $\mathrm{Mg}^{2+}-\mathrm{Si}^{4+}$ pairs leads to more pronounced tetragonal distortions/crystal field strength and hence larger $\Delta_{12}$ (red-shift), ${ }^{21,31}$ whereas a slight counteracting effect on $\varepsilon_{\mathrm{c}}$ (blue-shift) due to the change of the covalent character of the host material also occurs. ${ }^{21}$ A similar effect upon $\mathrm{Mg}^{2+}-\mathrm{Si}^{4+}$ co-substitution has also been observed in other types of phosphors, e.g. $\mathrm{Ca}_{2}\left(\mathrm{Al}_{1-x} \mathrm{Mg}_{x}\right)\left(\mathrm{Al}_{1-x} \mathrm{Si}_{1+x}\right) \mathrm{O}_{7}: \mathrm{Eu}^{2+}$, which tunes the emission color from the blue-green to the yellow-green region. ${ }^{32}$ The color of the emitted light can be also altered by the operation temperature of the phosphor, due to structural dynamics around the activator ions. ${ }^{10}$ For example, a general red-shift of the emission of $\mathrm{Ce}^{3+}$-doped $(\mathrm{Y}, \mathrm{Tb}, \mathrm{Gd})_{3} \mathrm{Al}_{5} \mathrm{O}_{12}$ garnet phosphors with increasing temperature has been observed in the limited temperature range of $300-450 \mathrm{~K},{ }^{6,26}$ although the mechanism causing the red-shift remains unclear.

Here, through a combined PL and Raman spectroscopy study on the three garnet type phosphors $\mathrm{Ce}^{3+}$-doped $\mathrm{Ca}_{3} \mathrm{Sc}_{2} \mathrm{Si}_{3} \mathrm{O}_{12}$ $\left(\mathrm{CSS}: \mathrm{Ce}^{3+}\right), \mathrm{Sr}_{3} \mathrm{Y}_{2} \mathrm{Ge}_{3} \mathrm{O}_{12}\left(\mathrm{SYG}: \mathrm{Ce}^{3+}\right)$ and YAG:Ce ${ }^{3+}$ with $1 \% \mathrm{Ce}^{3+}$, as well as YAG: $\mathrm{Ce}^{3+}$ with $2 \%$ and $3 \% \mathrm{Ce}^{3+}$, we investigate the effect of temperature on their PL properties over a large temperature range $(T=80-860 \mathrm{~K})$. The phosphors have in common that the $\mathrm{Ce}^{3+}$ ions substitute for the A site ions, which enables the investigation of both the effects of the garnet host type and $\mathrm{Ce}^{3+}$ concentration on the temperature dependent PL properties.

\section{Experimental}

\subsection{Sample preparation}

YAG:Ce ${ }^{3+}$ with 0, 1, 2 and $3 \mathrm{~mol} \% \mathrm{Ce}^{3+}$ doping, and CSS:Ce ${ }^{3+}$ and SYG:Ce ${ }^{3+}$ with 0 and $1 \mathrm{~mol} \% \mathrm{Ce}^{3+}$ doping, were prepared by conventional solid state synthesis. Details of the materials synthesis of YAG: $\mathrm{Ce}^{3+}$ can be found in ref. 33, whereas the respective details for CSS:Ce ${ }^{3+}$ and SYG:Ce ${ }^{3+}$ are available in ref. 11.

\subsection{Photoluminescence spectroscopy}

Variable temperature emission spectra of YAG:Ce ${ }^{3+}, \mathrm{CSS}: \mathrm{Ce}^{3+}$, and SYG:Ce ${ }^{3+}$ were recorded using a UV-vis spectrometer (USB2000+UV-VIS, Ocean Optics) coupled to an optical fiber with a $455 \mathrm{~nm}$ longpass colored glass filter (FGL455, Thorlabs) placed in front of the fiber inlet. Photon excitation was achieved using a $454 \mathrm{~nm}$ pulsed laser (DeltaDiode DD-450L from Horiba Scientific). Due to a background-like emission (manifested as a very weak and broad band over the range between 420 and $490 \mathrm{~nm}$ ) generated from the laser itself, which overlaps with the shorter wavelength emission bands of the studied phosphors, the laser light was further monochromatized by using a monochromator (300-800 nm Manual Mini-Chrom, Edmund Optics) prior to the excitation on the samples. The pulse structure of the laser was characterized by a width of about $80 \mathrm{ps}$ and a repetition rate of $100 \mathrm{MHz}$. Spectra were measured after a thermal equilibration time of $20 \mathrm{~s}$ over the temperature range $80-860 \mathrm{~K}$ with an interval of $20 \mathrm{~K}$ using a temperature controlled Linkam THMS 600 stage. Background spectra resulting 
from the UV-vis spectrometer itself were measured using the same settings as described above, but without the excitation at $454 \mathrm{~nm}$. The background spectra were then subtracted from the measured emission spectra of the garnet phosphors.

\subsection{Raman spectroscopy}

Variable temperature Raman spectra were measured on the three undoped ( $0 \mathrm{~mol} \% \mathrm{Ce}^{3+}$ ) compounds, YAG, CSS, and SYG, using a Renishaw InVia Reflex spectrometer equipped with a $532 \mathrm{~nm}$ laser, a CCD and a $2400 \mathrm{l} \mathrm{mm}^{-1}$ grating. Each spectrum was recorded for $10 \mathrm{~s}$ of acquisition time over 16 accumulations. The laser beam was focused on the sample through a $\times 50$ objective lens $(\mathrm{NA}=0.5)$ and the power of the laser on the surface of the samples was approximately $2 \mathrm{~mW}$. The temperature was controlled in the range of $80-850 \mathrm{~K}$ using the same temperature controlled stage as above.

\section{Results}

\subsection{Photoluminescence spectra}

The PL emission spectra of YAG:1\% $\mathrm{Ce}^{3+}$, YAG:2\% $\mathrm{Ce}^{3+}$, YAG:3\% $\mathrm{Ce}^{3+}$, CSS: $1 \% \mathrm{Ce}^{3+}$ and SYG:1\% $\mathrm{Ce}^{3+}$, measured over the temperature range of $80-860 \mathrm{~K}$ are shown in Fig. 2(a). For easier comparison between the different phosphors, the spectra have been scaled so that the maximum intensity of the lowesttemperature spectrum of each phosphor (except the spectrum for $\mathrm{SYG}: 1 \% \mathrm{Ce}^{3+}$ at $200 \mathrm{~K}$ ) is unity, whereas the respective scaling factors have been used for all temperatures.

The large intensity between approximately 13000 and $21000 \mathrm{~cm}^{-1}$ (here labelled as the $4 \mathrm{f}$ band) can be assigned to $\mathrm{Ce}^{3+} 5 \mathrm{~d}_{1} \rightarrow 4 \mathrm{f}$ emissive transitions. We observe that both the position and intensity of the bands show a strong dependence on temperature and vary significantly between the five different materials. For YAG: $\mathrm{Ce}^{3+}$, the position of the emission band (a)

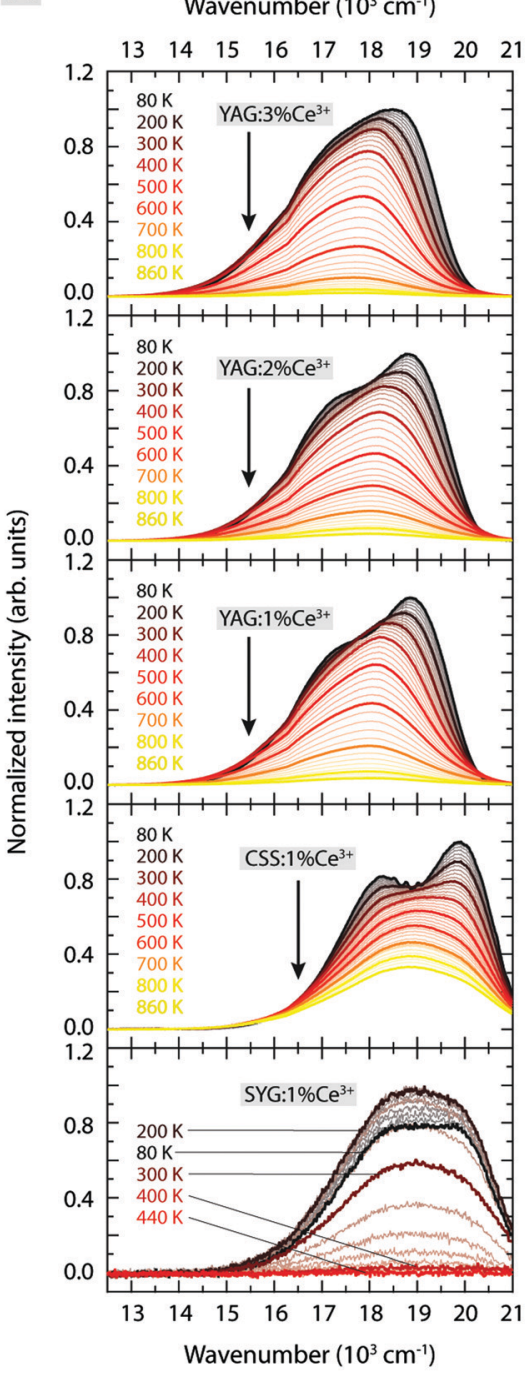

(b)

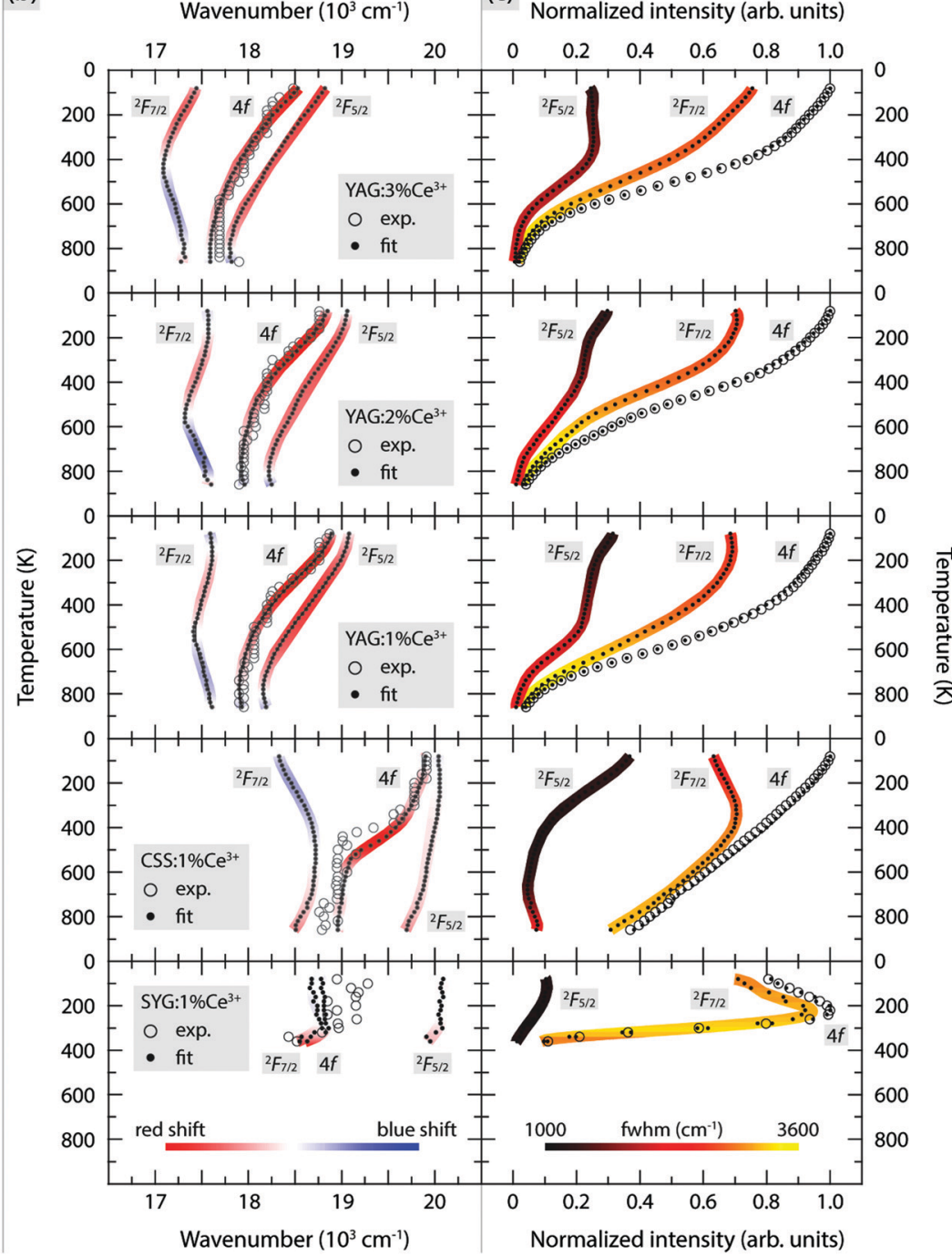

Fig. 2 Variable temperature (a) emission spectra, (b) positions of spectral band maxima as well as their shifts with respect to the temperature (indicated by the color code bar), and (c) integrated intensity of spectral bands together with their FWHMs (indicated by the color code bar), of YAG: $z \%$ Ce ${ }^{3+}(z=1,2$, and 3), CSS: $1 \% \mathrm{Ce}^{3+}$, and SYG:1\% $\mathrm{Ce}^{3+}$. 
maximum shifts to lower wavenumbers as a function of increasing $\mathrm{Ce}^{3+}$ concentration [e.g. $18870 \mathrm{~cm}^{-1}(530 \mathrm{~nm})$ for $1 \% \mathrm{Ce}^{3+}$, $18760 \mathrm{~cm}^{-1}(533 \mathrm{~nm})$ for $2 \% \mathrm{Ce}^{3+}$, and $18480 \mathrm{~cm}^{-1}(541 \mathrm{~nm})$ for $3 \% \mathrm{Ce}^{3+}$ at $T=80 \mathrm{~K}$. Such a wavenumber shift is commonly observed for various phosphors and results from increasing radiative energy transfer from higher to lower $5 \mathrm{~d}_{1}$ levels of $\mathrm{Ce}^{3+}$ ions through reabsorption processes..$^{25,26,33-36}$ The lowering of the $5 \mathrm{~d}_{1}$ level of $\mathrm{Ce}^{3+}$ may originate from the increased tetragonal distortions of the $\mathrm{CeO}_{8}$ moieties with increasing the $\mathrm{Ce}^{3+}$ concentration. ${ }^{10}$ By comparison, the emission band maxima of CSS: $\mathrm{Ce}^{3+}$ and SYG:Ce ${ }^{3+}$ are located at somewhat higher wavenumbers [e.g. at $19910 \mathrm{~cm}^{-1}(502 \mathrm{~nm})$ and $18950 \mathrm{~cm}^{-1}(528 \mathrm{~nm})$ at $T=80 \mathrm{~K}$, respectively]. Thus, the color of the emitted light is predominantly in the green-yellow range for YAG: $\mathrm{Ce}^{3+}$ and in the green range for CSS: $1 \% \mathrm{Ce}^{3+}$ and SYG:1\% $\mathrm{Ce}^{3+}$. This is further reflected by the color coordinates of the respective phosphors, as shown in the CIE 1931 diagram (Fig. 3).

We also observe a strong temperature dependence of the PL emission. For YAG: $\mathrm{Ce}^{3+}$, the color is systematically red-shifted as a function of increasing temperature up to about $T=740 \mathrm{~K}$, whereas for even higher temperatures, the color shifts towards the blue range for all three $\mathrm{Ce}^{3+}$ concentrations. For CSS: $\mathrm{Ce}^{3+}$ and SYG:Ce ${ }^{3+}$, the color coordinates are red-shifted up to the highest measurement temperature of $T=860 \mathrm{~K}\left(\mathrm{CSS}: \mathrm{Ce}^{3+}\right)$ and $T=360 \mathrm{~K}$ (SYG:Ce ${ }^{3+}$ ). The magnitude of the color change is for CSS: $\mathrm{Ce}^{3+}$ and SYG:Ce ${ }^{3+}$ relatively small, as it remains green

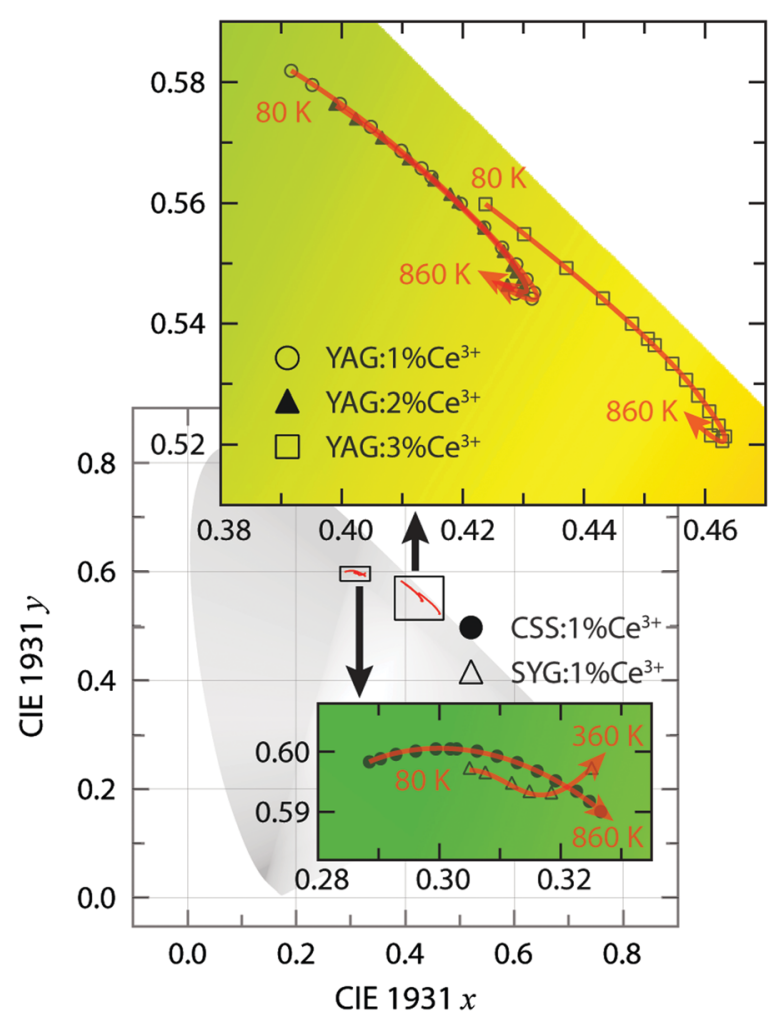

Fig. 3 Close-up views of the CIE 1931 color coordinate diagram for YAG: $z \% \mathrm{Ce}^{3+}(z=1,2$, and 3$)$ in the green-yellow region, CSS:1\% $\mathrm{Ce}^{3+}$, and $S Y G: 1 \% \mathrm{Ce}^{3+}$ in the green region, upon excitation at $454 \mathrm{~nm}$ with varying temperature. color, whereas for YAG:Ce ${ }^{3+}$ it changes from greenish-yellow to yellow color.

For a more detailed analysis of the emission spectra, we find that they can be adequately fitted to two Gaussian components, for all materials and temperatures (Fig. S1 and S2, ESI $\dagger$ ). A comparison to the literature suggests that these two components correspond to the radiative transitions from the $5 \mathrm{~d}_{1}$ level to the ${ }^{2} \mathrm{~F}_{5 / 2}$ and ${ }^{2} \mathrm{~F}_{7 / 2}$ states, ${ }^{12,18,37,38}$ but, in theory, it should be noted that such radiative transitions should be manifested by a total of seven components. ${ }^{39}$ However, here, the use of more than two Gaussians is not physically sound because the emission bands are, apparently, too close to be experimentally resolved.

Fig. 2(b and c) shows the relevant fit parameters, such as (b) the peak position, and (c) integrated intensity and full width at half maximum (FWHM) of each of the two Gaussians (here called ${ }^{2} \mathrm{~F}_{5 / 2}$ and ${ }^{2} \mathrm{~F}_{7 / 2}$ ), as well as for their sum (4f). Here, the color on the curves in Fig. 2(b) shows the shift of the emission maximum, with red color indicating a red-shift and with blue color indicating a blue-shift. The color shifts have been estimated by taking the first derivatives of temperature dependent polynomial functions that fit the data points of the emission maxima in Fig. 2(b).

For YAG:Ce ${ }^{3+}$, both maxima $\left({ }^{2} \mathrm{~F}_{5 / 2}\right.$ and $\left.{ }^{2} \mathrm{~F}_{7 / 2}\right)$ exhibit a strong temperature dependence. The ${ }^{2} \mathrm{~F}_{5 / 2}$ band undergoes a red-shift with increasing temperature up to around $T=800 \mathrm{~K}$, while, at even higher temperatures, it undergoes a slight blue-shift. This behavior is seen for all three $\mathrm{Ce}^{3+}$ concentrations. By comparison, the ${ }^{2} \mathrm{~F}_{7 / 2}$ band exhibits a red-shift with increasing temperature up to $520 \mathrm{~K}\left(1 \% \mathrm{Ce}^{3+}\right), 530 \mathrm{~K}\left(2 \% \mathrm{Ce}^{3+}\right)$ and $420 \mathrm{~K}\left(3 \% \mathrm{Ce}^{3+}\right)$, whereas upon further temperature increase, it shows a blue-shift. For the other two garnet phosphors, CSS:Ce ${ }^{3+}$ and SYG:Ce ${ }^{3+}$, the temperature dependence of the emission maximum for the two bands is notably different. For CSS: $\mathrm{Ce}^{3+}$, the ${ }^{2} \mathrm{~F}_{5 / 2}$ band exhibits a slight albeit systematic red-shift as a function of temperature up to the highest temperature of $T=860 \mathrm{~K}$, whereas the ${ }^{2} \mathrm{~F}_{7 / 2}$ band shows a blue-shift with increasing temperature from $T=80$ to $500 \mathrm{~K}$, after which it is red-shifted upon further temperature increase up to $T=860 \mathrm{~K}$. For SYG:Ce ${ }^{3+}$, the ${ }^{2} \mathrm{~F}_{5 / 2}$ and ${ }^{2} \mathrm{~F}_{7 / 2}$ bands turn from a virtually temperature independent behavior up to $T \approx 300 \mathrm{~K}$, to a red-shift with further increasing temperature up to $T=360 \mathrm{~K}$. For even higher temperatures, the luminescence is too weak to be analyzed reliably.

Fig. 2(c) shows the temperature dependence of the integrated intensity and FWHM for both bands $\left({ }^{2} \mathrm{~F}_{5 / 2}\right.$ and $\left.{ }^{2} \mathrm{~F}_{7 / 2}\right)$ as well as for the sum of their integrated intensity (4f), for all phosphors. For YAG: $\mathrm{Ce}^{3+}$, the integrated intensity of the three bands $\left(4 \mathrm{f},{ }^{2} \mathrm{~F}_{5 / 2}\right.$ and ${ }^{2} \mathrm{~F}_{7 / 2}$ ) is characterized by a relatively slow decrease with increasing temperature up to $T=400 \mathrm{~K}$ and a faster decrease for higher temperatures, for all three $\mathrm{Ce}^{3+}$ concentrations. The relatively weak decrease below $T=400 \mathrm{~K}$ can be related to a reduction of the absorption strength of the $4 \mathrm{f} \rightarrow 5 \mathrm{~d}_{1}$ transition, ${ }^{19,34}$ whereas the faster decrease at higher temperatures reflects the onset of thermal quenching of luminescence. ${ }^{10,34,40}$ For SYG:Ce ${ }^{3+}$, the integrated intensity of the $4 \mathrm{f}$ band exhibits a $20 \%$ increase when increasing the temperature from $T=80 \mathrm{~K}$ to $240 \mathrm{~K}$. The origin of this intensity increase is not explicitly clear here. Some recent studies 
suggested that this phenomenon is likely associated with crystal defects that may act as a center to store excitation energy or charges, which can interact with the excited state of the luminescent ions $\left(\mathrm{Ce}^{3+}\right)$ and further enhance the radiative emission. ${ }^{40-42}$ However, upon further temperature increase, the emission intensity decreases rapidly. At $T=400 \mathrm{~K}$, it is (within error) zero. A similar trend is also observed for the ${ }^{2} \mathrm{~F}_{5 / 2}$ and ${ }^{2} \mathrm{~F}_{7 / 2}$ bands. For CSS:Ce ${ }^{3+}$, the integrated emission intensity exhibits an almost linear decrease as a function of increasing temperature up to $T=860 \mathrm{~K}$. We note that this reduction in emission intensity has been related to a decrease in the absorption strength of the $4 \mathrm{f} \rightarrow 5 \mathrm{~d}_{1}$ transition. $^{11}$

By bringing together the PL results we observe some features common to the different phosphors: the ${ }^{2} \mathrm{~F}_{7 / 2}$ band has much stronger intensity and larger FWHM than the ${ }^{2} \mathrm{~F}_{5 / 2}$ band [Fig. 2(c)], indicating that the $\mathrm{Ce}^{3+}$ emission is primarily dominated by the $5 \mathrm{~d}_{1} \rightarrow{ }^{2} \mathrm{~F}_{7 / 2}$ transition, and the FWHMs of all bands progressively increase due to the thermal broadening effect. ${ }^{43}$

\subsection{Raman spectra}

Fig. 4 shows the variable temperature Raman spectra of YAG, CSS, and SYG. Considering first the lowest-temperature spectra, these are similar for the three different materials, with the number of distinguishable bands although, some of them, at different positions. Because the number of bands is related to the symmetry relations intrinsic to the garnet structure, and the chemical composition of the garnet host affects the vibrational frequencies, this is exactly what is expected. Considering next the spectra at higher temperatures, the bands show a general shift towards lower frequencies as a result of lattice expansion. ${ }^{10}$

\section{Discussion}

\subsection{The effect of the garnet host lattice on the emission color}

In regard to the reason for the color difference of the emitted light between the three phosphors, it has been shown that the shorter wavelength emission for CSS:Ce ${ }^{3+}$ (green) and SYG:Ce ${ }^{3+}$ (green) as compared to YAG:Ce ${ }^{3+}$ (green-yellow) mainly originates from the higher energy of the ${ }^{2} E_{\mathrm{g}}$ barycenter (in $O_{\mathrm{h}}$ notation) of the $\mathrm{Ce}^{3+} 5 \mathrm{~d}$ levels ( $c f$. Table 1$) .{ }^{11}$ As the ${ }^{2} E_{\mathrm{g}}$ values are mainly determined by the centroid shift $\varepsilon_{\mathrm{c}}$ and the cubal crystal field splitting $\Delta$, of which $\Delta$ is inversely proportional to the Ce-O bond length $(R)$ to a power of $5,{ }^{12,16}$ the higher ${ }^{2} E_{\mathrm{g}}$ for SYG:Ce ${ }^{3+}$ with respect to YAG:Ce ${ }^{3+}$ may thus be explained by the larger $R$ value for SYG:Ce ${ }^{3+}(c f .2 .62 \AA$ vs. $2.45 \AA$, see Table 1). For CSS: $\mathrm{Ce}^{3+}$ and YAG: $\mathrm{Ce}^{3+}$, the $R$ values are, however, almost exactly the same ( $c f .2 .46 \AA$ v. $2.45 \AA$, see Table 1), suggesting that the magnitude of $\Delta$ may not be the main cause for the higher ${ }^{2} E_{\mathrm{g}}$ value for $\mathrm{CSS}: \mathrm{Ce}^{3+}$. In effect, this suggests that CSS:Ce ${ }^{3+}$ exhibits a smaller $\varepsilon_{\mathrm{c}}$ than YAG: $\mathrm{Ce}^{3+}$.

$\varepsilon_{\mathrm{c}}$ depends on the covalency of the $\mathrm{Ce}-\mathrm{O}$ bond and the polarizability of the surrounding $\mathrm{O}$ anions $(\alpha) \cdot{ }^{12}$ Generally, a high $\mathrm{Ce}-\mathrm{O}$ covalency requires an extensive overlap between the $\mathrm{Ce}^{3+} 5 \mathrm{~d}$ orbital and the $2 \mathrm{p}$ orbitals of the $\mathrm{O}$ ligands, which thus corresponds to short Ce-O distances $(R) .{ }^{8,14,15}$ The fact that the Ce-O distances for YAG: $\mathrm{Ce}^{3+}$ and $\mathrm{CSS}: \mathrm{Ce}^{3+}$ are comparable suggests, however, that its effect on $\varepsilon_{\mathrm{c}}$ is negligible compared to the effect of $\alpha$, which may be approximately correlated with $\varepsilon_{\mathrm{c}}$ using the relation: $\varepsilon_{\mathrm{c}} \propto \alpha \cdot R^{-6}$. Physically, $\alpha$ scales approximately linearly with $\chi_{\mathrm{av}}{ }^{-2}$, where $\chi_{\mathrm{av}}$ is the average cation electronegativity in the material ${ }^{14}$ and as compiled for the three phosphors in Table 1 . CSS: $\mathrm{Ce}^{3+}$ is characterized by a smaller

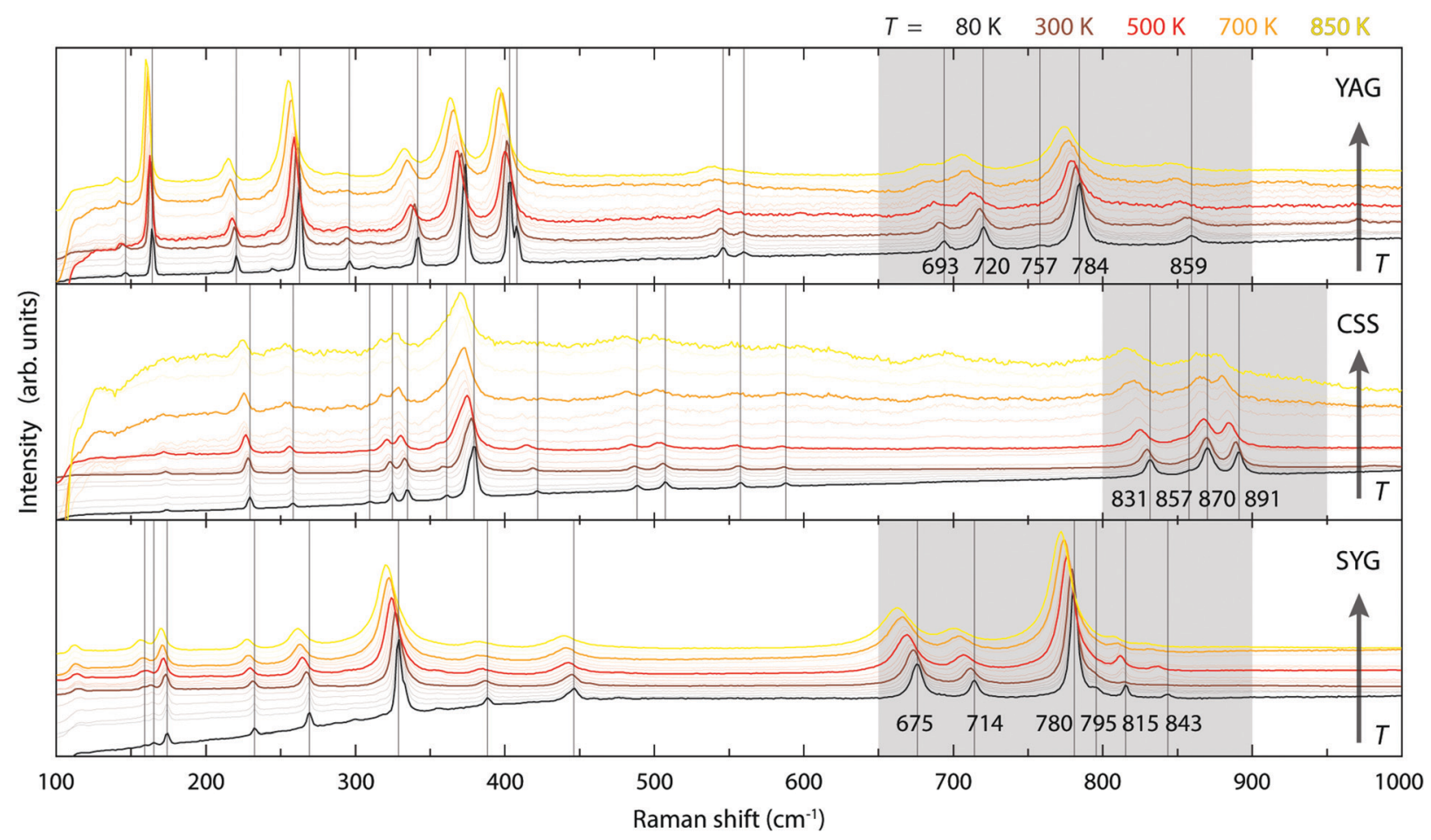

Fig. 4 Variable temperature Raman spectra of YAG, CSS, and SYG over the range of 80-850 K. 
Table 1 Structural, chemical, and luminescence properties of $\mathrm{A}_{3} \mathrm{~B}_{2} \mathrm{C}_{3} \mathrm{O}_{12}$ $\mathrm{Ce}^{3+}$, where $\mathrm{A}=\mathrm{Y}, \mathrm{B}=\mathrm{Al}$, and $\mathrm{C}=\mathrm{Al}$ for $\mathrm{YAG}: \mathrm{Ce}^{3+} ; \mathrm{A}=\mathrm{Ca}, \mathrm{B}=\mathrm{SC}$, and $C=$ Si for CSS: $\mathrm{Ce}^{3+} ; A=\mathrm{Sr}, \mathrm{B}=\mathrm{Y}$, and $\mathrm{C}=\mathrm{Ge}$ for SYG:Ce ${ }^{3+}$

\begin{tabular}{lllllllll}
\hline Sample & $\begin{array}{l}{ }^{2} E_{\mathrm{g}}{ }^{11} \\
\left(\mathrm{~cm}^{-1}\right)\end{array}$ & $R(\AA)$ & $\chi_{\mathrm{A}}{ }^{44}$ & $\chi_{\mathrm{B}}{ }^{44}$ & $\chi_{\mathrm{C}}{ }^{44}$ & $\chi_{\mathrm{av}}{ }^{-2 a}$ & $\begin{array}{l}\Delta_{12}{ }^{11} \\
\left(\mathrm{~cm}^{-1}\right)\end{array}$ & $d_{88} / d_{81}$ \\
\hline YAG:Ce $^{3+}$ & 25344 & $2.45^{33}$ & 1.22 & 1.61 & 1.61 & 0.4668 & 8135 & $0.986^{b}$ \\
CSS:Ce $^{3+}$ & 28908 & $2.46^{22}$ & 1.00 & 1.36 & 1.90 & 0.4217 & 12360 & $1.011^{c}$ \\
SYG:Ce $^{3+}$ & 28545 & $2.62^{45}$ & 0.95 & 1.22 & 2.01 & 0.4176 & 10251 & $1.004^{d}$
\end{tabular}

${ }^{a} \chi_{\mathrm{av}}=\sum_{i=1}^{N_{\mathrm{c}}} z_{\mathrm{c} i} \chi_{\mathrm{c} i} / \sum_{i=1}^{N_{\mathrm{a}}} z_{\mathrm{a} i}$, where $N_{\mathrm{c}}$ and $N_{\mathrm{a}}$ are the numbers of cations and anions, respectively, and $z_{\mathrm{c} i}$ and $z_{\mathrm{a} i}$ are their respective valence charges, and $\chi_{\mathrm{c} i}$ is the corresponding cation electronegativity, i.e. $\chi_{\mathrm{A}}, \chi_{\mathrm{B}}$ or $\chi_{\mathrm{C}}{ }^{b}{ }^{b}$ Estimated from YAG $\left(d_{88}=2.859 \AA\right.$ and $\left.d_{81}=2.899 \AA\right)$ from ref. 46 . ${ }^{c}$ Estimated from CSS:Ce ${ }^{3+}\left(d_{88}=2.921 \AA\right.$ and $\left.d_{81}=2.890 \AA\right)$ from ref. 22. ${ }^{d}$ Estimated from SYG $\left(d_{88}=3.0834 \AA\right.$ and $\left.d_{81}=3.0707 \AA\right)$ from ref. 45.

$\chi_{\mathrm{av}}{ }^{-2}$ than YAG:Ce ${ }^{3+}$ (Table 1$)$. This correlates with smaller $\alpha$, which explains the higher ${ }^{2} E_{\mathrm{g}}$ and the shorter wavelength emission for CSS:Ce ${ }^{3+}$, as compared to that for YAG:Ce ${ }^{3+}$.

\subsection{The effect of structural dynamics on the emission color}

The three effects discussed so far, i.e. the cubal crystal field splitting $\Delta$, Ce-O covalency, and anion polarizability $\alpha$, are all affected in a way that an increase of the $\mathrm{Ce}-\mathrm{O}$ bond distance results in an upward-shift of the ${ }^{2} E_{\text {g }}$, which in turn should be manifested as a blue-shift of the color of the emitted light. Nonetheless, the (local) lattice expansion (Fig. 4) and red-shift of the emitted light (Fig. 2 and 3) as a function of increasing temperature, suggest that a, thermally dependent, counteracting and predominating, mechanism is the main cause for the observed temperature tuning of the emission color. As the emission arises from electronic transitions from the lowest $5 d$ level $\left(5 d_{1}\right)$, one possible explanation for the thermally-induced red-shift may be an increase of the tetragonal crystal field splitting $\Delta_{12}$ (Fig. 1), due to increased tetragonal structural distortions of the $\mathrm{CeO}_{8}$ moieties. In theory, such a distortion could be purely static in nature, similarly to the effect of, e.g., cation substitution, and/or imposed by structural dynamics. ${ }^{10,26}$ In regard to the latter, Seijo et $a l^{47}$ showed that the only deformations of a $\mathrm{CeO}_{8}$ moiety found to shift the lowest $5 \mathrm{~d}-4 \mathrm{f}$ transition to lower energy (red-shift) are symmetric $\mathrm{Ce}-\mathrm{O}$ bond compression and tetragonally symmetric bond bending, which are assigned to the $\mathrm{A}_{1 \mathrm{~g}}$ and $\mathrm{E}_{\mathrm{g}}$ symmetries of a cubal $\mathrm{CeO}_{8}$ unit (belonging to the $O_{\mathrm{h}}$ point symmetry group), respectively. Recently, we showed for YAG that the symmetric Ce-O bond compression [the $\mathrm{A}_{1 \mathrm{~g}}$ stretching (S) vibration] and symmetric $\mathrm{Ce}-\mathrm{O}$ bond bending [the $\mathrm{E}_{\mathrm{g}}$ bending (B) vibration], are found primarily in the medium-to-high frequency regions of the vibrational spectra, as highlighted here by the $2 \mathrm{D}$ phonon decomposition map (PDM) shown in Fig. 5 (the full PDMs are shown in ref. 10). In particular, the strongest $A_{1 g} S$ and $E_{g} \mathbf{B}$ character for the YAG host can be found in the spectral range of $520-860 \mathrm{~cm}^{-1}$ for the Raman modes $\left(\mathrm{R}_{16}-\mathrm{R}_{19}, \mathrm{R}_{21}, \mathrm{R}_{24}\right.$ and $\left.\mathrm{R}_{25}\right)$, and in the range of $390-860 \mathrm{~cm}^{-1}$ for the silent modes $\left(\mathrm{Si}_{27}, \mathrm{Si}_{41}\right.$, $\mathrm{Si}_{43}, \mathrm{Si}_{51}, \mathrm{Si}_{52}$ and $\mathrm{Si}_{55}$ ). For CSS and SYG, the corresponding Raman modes are located in the range of i.e. $800-950 \mathrm{~cm}^{-1}$ (CSS) and 650-900 $\mathrm{cm}^{-1}$ (SYG), see Fig. 4, based on the fact that the three host materials have the same crystal structure so

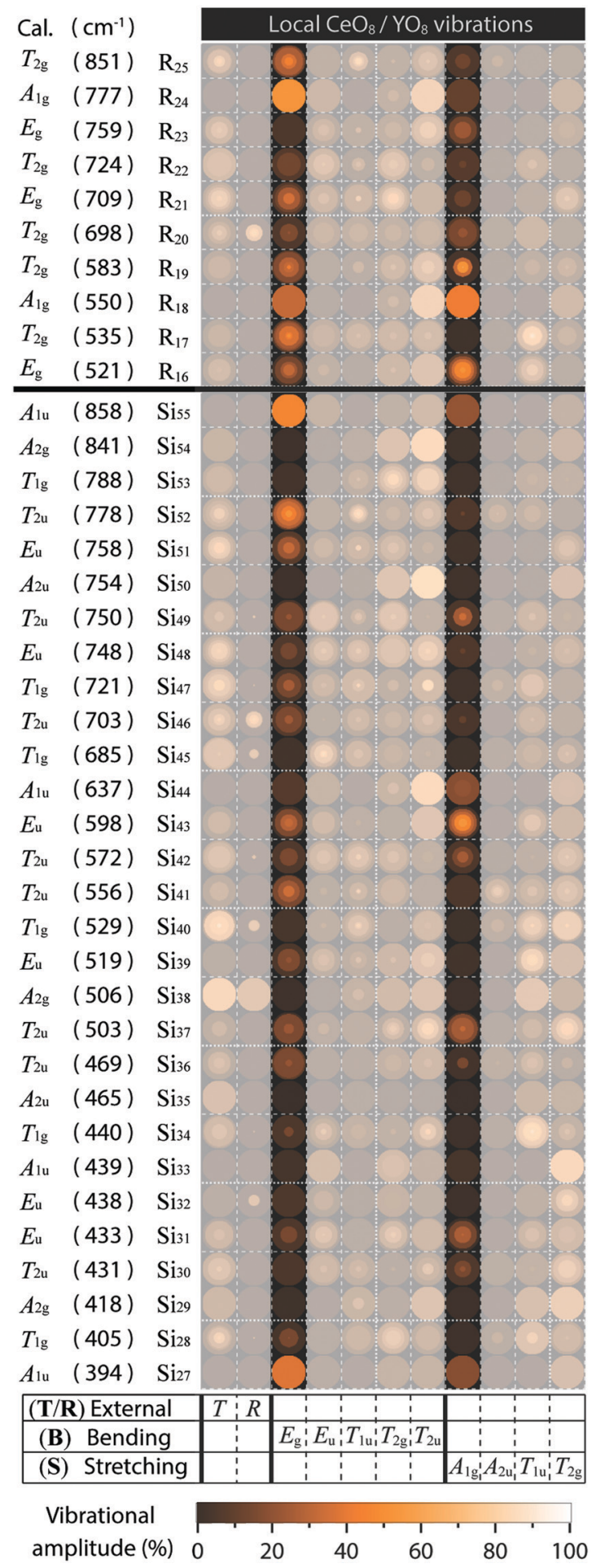

Fig. 5 Partial PDM focusing on the contribution of $E_{g} \mathbf{B}$ and $A_{1 g} \mathbf{S}$ modes involving $\mathrm{CeO}_{8} / \mathrm{YO}_{8}$ moieties to medium-to-high frequency Raman and silent modes of YAG/YAG: $\mathrm{Ce}^{3+}$.

that, qualitatively, the (local) vibrational symmetry properties in relation to the vibrational frequency should be the same. ${ }^{48}$ It follows that the excitation of these vibrational modes should cause a red-shift of the emitted light for all the three phosphors, YAG:Ce ${ }^{3+}, \mathrm{CSS}: \mathrm{Ce}^{3+}$ and SYG:Ce ${ }^{3+}$. 
Fig. 2(b) shows how the red-shift of the ${ }^{2} \mathrm{~F}_{7 / 2}$ band of YAG: $\mathrm{Ce}^{3+}$ occurs up to a temperature of $520 \mathrm{~K}$ for $1 \% \mathrm{Ce}^{3+}$, $530 \mathrm{~K}$ for $2 \% \mathrm{Ce}^{3+}$, and $420 \mathrm{~K}$ for $3 \% \mathrm{Ce}^{3+}$, whereas the ${ }^{2} \mathrm{~F}_{5 / 2}$ band exhibits a red-shift up to about $800 \mathrm{~K}$ for all three $\mathrm{Ce}^{3+}$ concentrations. At even higher temperatures, the emission becomes blue-shifted and, generally, the ${ }^{2} \mathrm{~F}_{7 / 2}$ and ${ }^{2} \mathrm{~F}_{5 / 2}$ bands exhibit a red-to-blue shift with increasing temperature, however with different transition temperatures. In this context, we note also the apparent decrease in the separation between the ${ }^{2} \mathrm{~F}_{7 / 2}$ and ${ }^{2} \mathrm{~F}_{5 / 2}$ states (Fig. 6) as observed from our fitting results [Fig. 2(b)], which implies a blue-shifting effect on the $5 \mathrm{~d}_{1}-{ }^{2} \mathrm{~F}_{7 / 2}$ emission and a red-shifting effect on the $5 \mathrm{~d}_{1}-{ }^{2} \mathrm{~F}_{5 / 2}$ emission. This is in agreement and may explain the higher transition temperature observed for the ${ }^{2} F_{5 / 2}$ band. However, the physical origin of this observed energy reduction between the ${ }^{2} \mathrm{~F}_{5 / 2}$ and ${ }^{2} \mathrm{~F}_{7 / 2}$ states is at present unclear. Speculatively, it could be related to a decrease of the spin-orbit coupling strength and/or to the different temperature dependence of the electronic-vibrational transitions between the two bands, but caution should be taken that it is not just an effect of the peak deconvolution.

Strikingly, the temperature range in which the transition from red-shift to blue-shift occurs, is comparable to the Debye temperature of YAG: $\mathrm{Ce}^{3+}, \Theta_{\mathrm{D}}>500 \mathrm{~K}^{10,33} \Theta_{\mathrm{D}}$ provides a measure of the temperature at which the vibrational density of states becomes fully populated, which, in our case, correspond to exactly those phonon modes that induce dynamical tetragonal distortions of the $\mathrm{CeO}_{8}$ moieties in the garnet phosphors, and it reflects the stiffness of the lattice of the material. The observation that the transition from red-shift to blue-shift occurs around $\Theta_{\mathrm{D}}$ suggests that when the vibrations enhancing tetragonal distortions of the $\mathrm{CeO}_{8}$ moieties are thermally fully populated, there is a counteracting effect that suppresses the degree of tetragonal distortions and effectively reverses the optical response. We attribute this counteracting effect to thermal lattice expansion, which weakens the tetragonal distortion of $\mathrm{CeO}_{8}$ since the $\mathrm{Ce}-\mathrm{O}$ bonds are thermally elongated and, hence, the $\mathrm{CeO}_{8}$ moiety approaches a more cubal symmetry that reduces $\Delta_{12}$ (Fig. 1). ${ }^{23}$ Furthermore, we observe that the frequencies of the high-frequency modes

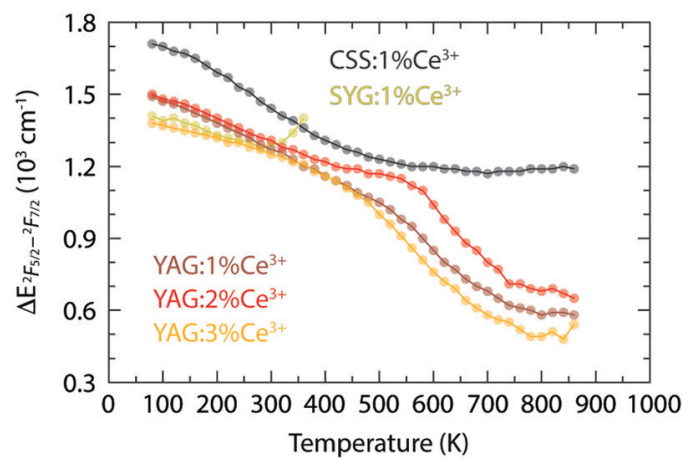

Fig. 6 Variable temperature energy difference between the maxima of the ${ }^{2} \mathrm{~F}_{5 / 2}$ and ${ }^{2} \mathrm{~F}_{7 / 2}$ bands for YAG: $: \% \mathrm{Ce}^{3+}(z=1,2$, and 3$), \mathrm{CSS}: 1 \% \mathrm{Ce}^{3+}$, and SYG:1\% $\mathrm{Ce}^{3+}$, which are calculated from the fitting results shown in Fig. 2(b). Note that the results of SYG: $\mathrm{Ce}^{3+}$ at the last two points $(340 \mathrm{~K}$ and $360 \mathrm{~K})$ appear to behave unexpectedly, which may be explained by the fitting errors due to relatively low intensity of the spectra (Fig. S1, ESI ). associated with the $\mathrm{E}_{\mathrm{g}} \mathrm{B}$ vibrations of $\mathrm{CeO}_{8}$ in the YAG host lattice, e.g., $\mathrm{R}_{17}, \mathrm{R}_{24}$ and $\mathrm{R}_{25}$, show a slight but significant downshift when the $\mathrm{Ce}^{3+}$ concentration increases from 1 or $2 \%$ to $3 \%$, see ref. 10 . This is in agreement with the reported $\Theta_{D}$ that is lower for higher $\mathrm{Ce}^{3+}$ concentration $^{10,33}$ and suggests that the transition temperature of the red-to-blue shift is expected to be lower for $3 \% \mathrm{Ce}^{3+}$, which is as well in accordance with the observation of the shift of the band maximum of YAG: $z \% \mathrm{Ce}^{3+}$ [Fig. 2(b)].

In contrast to YAG:Ce ${ }^{3+}, \mathrm{CSS}: \mathrm{Ce}^{3+}$ exhibits a reversed behavior for the ${ }^{2} \mathrm{~F}_{7 / 2}$ band, as it evolves from a continuous blue-shift upon increasing temperature, up to $500 \mathrm{~K}$, to a red-shift for even higher temperatures [Fig. 2(b)]. This behavior would rather suggest that the effect of the decreasing separation distance between the ${ }^{2} \mathrm{~F}_{7 / 2}$ and ${ }^{2} \mathrm{~F}_{5 / 2}$ states is stronger than the effect caused by the thermally-induced tetragonal distortions of the $\mathrm{CeO}_{8}$ moieties. This may be already hinted by the comparatively faster decrease below $500 \mathrm{~K}$ (Fig. 6), but is also in line with the larger $\Theta_{\mathrm{D}}$ for CSS: $\mathrm{Ce}^{3+}$, as compared to YAG: $\mathrm{Ce}^{3+}$, which is inferred from a simple comparison of the highest frequency of the Raman modes between the two materials (highlighted in gray areas in Fig. 4). Additionally, the relevant vibrational modes, in the range of 800-950 $\mathrm{cm}^{-1}$, appear to be more rigid against a temperature increase (Fig. 7), suggesting that they require more thermal energy to become fully activated for CSS: $\mathrm{Ce}^{3+}$ compared to YAG: $\mathrm{Ce}^{3+}$. For SYG:Ce ${ }^{3+}$, we lack emission data for $T>360 \mathrm{~K}$, and therefore the effect of dynamical tetragonal distortions and the (possible) change in the separation between the ${ }^{2} \mathrm{~F}_{7 / 2}$ and ${ }^{2} \mathrm{~F}_{5 / 2}$ states cannot be adequately analyzed.

Turning now to a more quantitative analysis of the effect of vibrational modes on the PL emission colors, we note that, while $\Theta_{\mathrm{D}}$ allows one to estimate the thermal energy required for fully populating the vibrational modes inducing tetragonal distortions of the $\mathrm{CeO}_{8}$ moiety in garnet phosphors, it does not provide a measure of the vibrational amplitude, i.e. the magnitude of the tetragonal distortions. The degree of tetragonal distortions is measured here by a distortion parameter defined as the ratio of the long to short O-O distances $\left(d_{1} / d_{\mathrm{s}}\right)$ for a cuballike $\mathrm{CeO}_{8} / \mathrm{YO}_{8}$ moiety, as illustrated in Fig. 8(a) for the doubly degenerated $\mathrm{E}_{\mathrm{g}} \mathbf{B}$ vibrations in YAG: $\mathrm{Ce}^{3+}$. The so obtained $d_{\mathrm{l}} / d_{\mathrm{s}}$

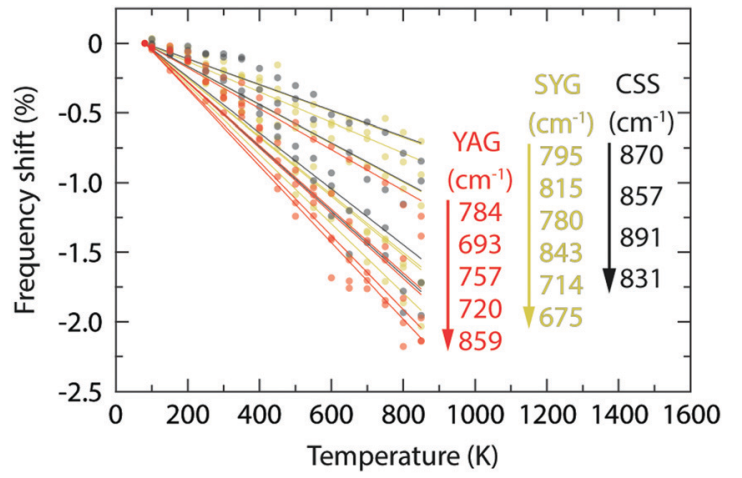

Fig. 7 Variation of the vibrational frequency for the Raman-active modes of YAG, CSS, and SYG, as a function of increasing temperature, revealing a more pronounced softening for YAG lattice than for CSS and SYG lattices. 
ratio as a function of excitation of the different vibrational modes reveals that strong tetragonal distortions mainly arise from modes in the wavenumber region $500-900 \mathrm{~cm}^{-1}$ and one silent mode at $\approx 400 \mathrm{~cm}^{-1}$ [Fig. 8(b)]. The $d_{1} / d_{\mathrm{s}}$ ratio increases by as much as $\approx 7 \%$ when the strongest $\mathrm{E}_{\mathrm{g}} \mathbf{B}$ vibration is fully activated at $T=\Theta_{\mathrm{D}}$, which coincides with a decrease of the energy of the maximum of the $4 \mathrm{f}$ emission band by, e.g., $\approx 820$ $\mathrm{cm}^{-1}$ for YAG:1\% Ce ${ }^{3+}$ [Fig. 2(b)]. Since the $d_{\mathrm{l}} / d_{\mathrm{s}}$ values are estimated using the maximum vibrational amplitude, the effective vibrational amplitude is approximately half of the maximum, i.e. $3.5 \%$, under the assumption that the modes are harmonic in

(a)

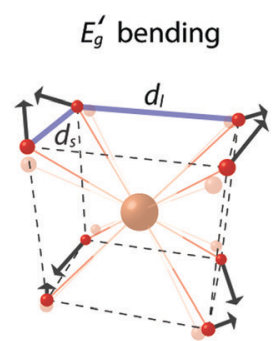

(b)

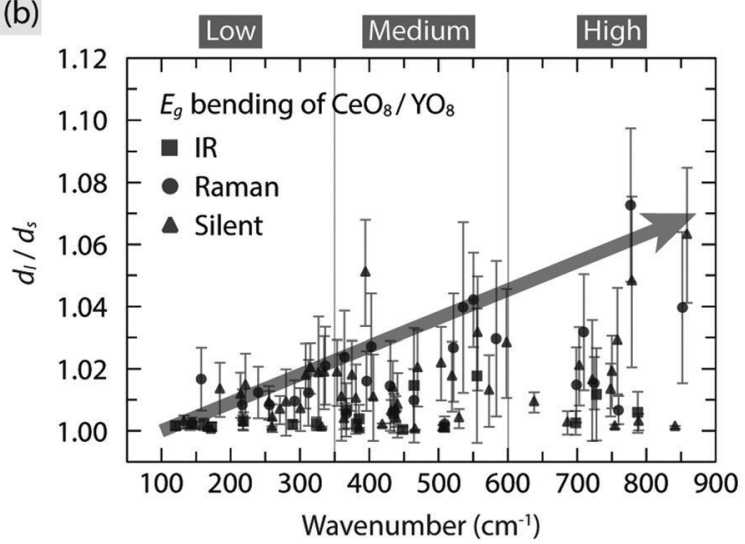

(c)

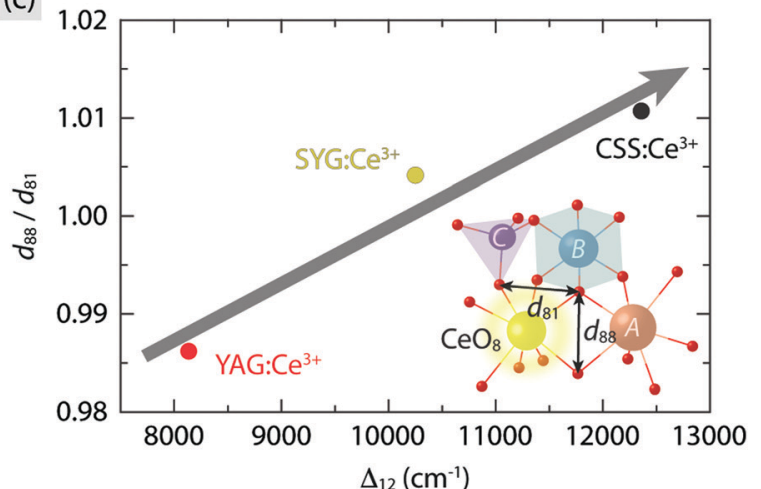

Fig. 8 (a) Illustration of the doubly degenerate $E_{g} \mathbf{B}$ modes of cubal $\mathrm{CeO}_{8} / \mathrm{YO}_{8}$ moieties based on their symmetry coordinates. (b) Dynamical distortion parameter $\left(d_{1} / d_{s}\right)$, as marked in (a), for the $E_{g}$ B modes of the $\mathrm{CeO}_{8} / \mathrm{YO}_{8}$ moieties in YAG: $\mathrm{Ce}^{3+}$ for all vibrational modes, extracted from ref. 10. (c) Relation between the static distortion parameter $\left(d_{88} / d_{81}\right)$ and the tetragonal crystal field splitting $\left(\Delta_{12}\right)$ for YAG:Ce ${ }^{3+}, \mathrm{CSS}: \mathrm{Ce}^{3+}$, and SYG: $\mathrm{Ce}^{3+}$. Inset illustrates part of polyhedral network in the garnet structure in relation to the distortion parameter $d_{88} / d_{81}$, i.e. the ratio of the two $\mathrm{O}-\mathrm{O}$ distances of the dodecahedron as denoted in the figure. ${ }^{24,46}$ nature. By comparison, the similar garnet phosphors $\mathrm{Y}_{3} \mathrm{Al}_{5-y} \mathrm{Ga}_{y} \mathrm{O}_{12}: \mathrm{Ce}^{3+}$ have been found to exhibit a red-shift of the emission maximum from 504 to $540 \mathrm{~nm}$ (a difference of $\approx 1300$ $\mathrm{cm}^{-1}$ ) upon an increase of the analogous distortion parameter $d_{88} / d_{81}$, as defined in the inset of Fig. $8(\mathrm{c})$, by $\approx 4 \% .{ }^{23}$ It follows that the dynamical tetragonal distortions of $\mathrm{CeO}_{8}$, as determined in this work, have a very comparable effect on the red-shift as the static tetragonal distortions of $\mathrm{CeO}_{8}$.

To compare the effect of static tetragonal distortions of $\mathrm{CeO}_{8}$ between different garnet hosts, the $d_{88} / d_{81}$ values for YAG:Ce ${ }^{3+}$, CSS: $\mathrm{Ce}^{3+}$, and SYG:Ce ${ }^{3+}$ are also calculated here using crystallographic data of respective garnet crystals (Table 1) and used as a measure for the degree of the static tetragonal distortions of $\mathrm{CeO}_{8}$. In good agreement with our spectroscopic results, the magnitude of $d_{88} / d_{81}$ is found to scale almost linearly with the magnitude of $\Delta_{12}$ (Table 1) for the three garnet phosphors [Fig. 8(c)]. It is worth noting that an increase of $d_{88} / d_{81}$ by $2 \%$ leads to an increase of $\Delta_{12}$ by $\approx 4200 \mathrm{~cm}^{-1}$ (Table 1 ), which suggests that the control of the local (tetragonal) lattice distortions around $\mathrm{Ce}^{3+}$ through complete cation co-substitution affects significantly the color of the PL.

\section{Conclusions}

In conclusion, we have shown that the red-shift of the PL emission as a function of increasing temperature generally observed in YAG:Ce ${ }^{3+}, \mathrm{CSS}: \mathrm{Ce}^{3+}$, and SYG:Ce ${ }^{3+}$ garnet phosphors is the result of thermally activated dynamical tetragonal distortions of the $\mathrm{CeO}_{8}$ moieties. The relevant vibrational modes exhibiting this type of dynamical lattice distortions are mainly associated with symmetric $\mathrm{E}_{\mathrm{g}}$ bending of $\mathrm{CeO}_{8}$ with relatively high vibrational frequencies of the lattice modes. The frequency (rigidity) as well as the amplitude (degree of the tetragonal distortion) of these vibrational modes determines the magnitude of the red-shift at a given temperature, which is influenced by the $\mathrm{Ce}^{3+}$ dopant concentration and the chemical compositions of the garnet host. The reversal of wavelength shift, as observed in YAG: $\mathrm{Ce}^{3+}$ with increasing temperature up to around $500 \mathrm{~K}$, occurs when these modes are fully populated. At higher temperatures, the effect of thermal lattice expansion becomes overwhelming, which leads to a more cubal-like local environment of the $\mathrm{CeO}_{8}$ moieties. Since this behavior is the result of the symmetry relations intrinsic to the garnet structure, the mechanisms described here can be expected to be generally applicable to materials of this type.

\section{Conflicts of interest}

There are no conflicts to declare.

\section{Acknowledgements}

M. K. thanks the Swedish Research Council Formas for funding (Grant No. 2013-1723). The group of R. Seshadri, UCSB, is thanked for providing the series of YAG: $\mathrm{Ce}^{3+}$ samples. The group of M. Bettinelli, University of Verona, is thanked for 
the synthesis of the CSS:Ce ${ }^{3+}$ and SYG:Ce ${ }^{3+}$ samples and for fruitful discussions.

\section{References}

1 S. Pimputkar, J. S. Speck, S. P. DenBaars and S. Nakamura, Nat. Photonics, 2009, 3, 180-182.

2 Y.-C. Lin, M. Karlsson and M. Bettinelli, Top. Curr. Chem., 2016, 374, 1-47.

3 P. F. Smet, A. B. Parmentier and D. Poelman, J. Electrochem. Soc., 2011, 158, R37-R54.

4 M. R. Krames, O. B. Shchekin, R. Mueller-Mach, G. O. Mueller, L. Zhou, G. Harbers and M. G. Craford, J. Disp. Technol., 2007, 3, 160-175.

5 S. Ye, F. Xiao, Y. X. Pan, Y. Y. Ma and Q. Y. Zhang, Mater. Sci. Eng., $R$, 2010, 71, 1-34.

6 C. C. Lin and R.-S. Liu, J. Phys. Chem. Lett., 2011, 2, 1268-1277.

7 Z. Xia and A. Meijerink, Chem. Soc. Rev., 2017, 46, 275-299.

8 X. Qin, X. Liu, W. Huang, M. Bettinelli and X. Liu, Chem. Rev., 2017, 117, 4488-4527.

9 S. Geller, Z. Kristallogr., 1967, 125, 1-47.

10 Y.-C. Lin, P. Erhart, M. Bettinelli, N. C. George, S. F. Parker and M. Karlsson, Chem. Mater., 2018, 30, 1865-1877.

11 S. K. Sharma, Y.-C. Lin, I. Carrasco, T. Tingberg, M. Bettinelli and M. Karlsson, J. Mater. Chem. C, 2018, 6, 8923-8933.

12 N. C. George, K. A. Denault and R. Seshadri, Annu. Rev. Mater. Res., 2013, 43, 481-501.

13 P. Dorenbos, J. Lumin., 2013, 134, 310-318.

14 P. Dorenbos, Phys. Rev. B: Condens. Matter Mater. Phys., 2002, 65, 235110.

15 P. Dorenbos, J. Lumin., 2002, 99, 283-299.

16 P. D. Rack and P. H. Holloway, Mater. Sci. Eng., R, 1998, 21, 171-219.

17 E. G. Rogers and P. Dorenbos, J. Lumin., 2014, 155, 135-140.

18 A. Kaminska, A. Duzynska, M. Berkowski, S. Trushkin and A. Suchocki, Phys. Rev. B: Condens. Matter Mater. Phys., 2012, 85, 155111.

19 D. Robbins, J. Electrochem. Soc., 1979, 126, 1550-1555.

20 Z. Xia and Q. Liu, Prog. Mater. Sci., 2016, 84, 59-117.

21 A. A. Setlur, W. J. Heward, Y. Gao, A. M. Srivastava, R. G. Chandran and M. V. Shankar, Chem. Mater., 2006, 18, 3314-3322.

22 F. Pan, M. Zhou, J. Zhang, X. Zhang, J. Wang, L. Huang, X. Kuang and M. Wu, J. Mater. Chem. C, 2016, 4, 5671-5678.

23 J. L. Wu, G. Gundiah and A. Cheetham, Chem. Phys. Lett., 2007, 441, 250-254.

24 A. Kalaji, P. J. Saines, N. C. George and A. K. Cheetham, Chem. Phys. Lett., 2013, 586, 91-96.

25 A. Setlur and A. Srivastava, Opt. Mater., 2007, 29, 1647-1652.

26 C.-C. Chiang, M.-S. Tsai and M.-H. Hon, J. Electrochem. Soc., 2008, 155, B517-B520.
27 Q. Shao, Y. Dong, J. Jiang, C. Liang and J. He, J. Lumin., 2011, 131, 1013-1015.

28 T. Y. Tien, E. F. Gibbons, R. G. DeLosh, P. J. Zacmanidis, D. E. Smith and H. L. Stadler, J. Electrochem. Soc., 1973, 120, 278-281.

29 Y. X. Pan, W. Wang, G. K. Liu, S. Skanthakumar, R. A. Rosenberg, X. Z. Guo and K. K. Li, J. Alloys Compd., 2009, 488, 638-642.

30 Y. Kanke and A. Navrotsky, J. Solid State Chem., 1998, 141, 424-436.

31 H. Ji, L. Wang, M. S. Molokeev, N. Hirosaki, R. Xie, Z. Huang, Z. Xia, M. Otmar, L. Liu and V. V. Atuchin, J. Mater. Chem. C, 2016, 4, 6855-6863.

32 Z. Xia, C. Ma, M. S. Molokeev, Q. Liu, K. Rickert and K. R. Poeppelmeier, J. Am. Chem. Soc., 2015, 137, 12494-12497.

33 N. C. George, A. J. Pell, G. Dantelle, K. Page, A. Llobet, M. Balasubramanian, G. Pintacuda, B. F. Chmelka and R. Seshadri, Chem. Mater., 2013, 25, 3979-3995.

34 V. Bachmann, C. Ronda and A. Meijerink, Chem. Mater., 2009, 21, 2077-2084.

35 V. Bachmann, C. Ronda, O. Oeckler, W. Schnick and A. Meijerink, Chem. Mater., 2008, 21, 316-325.

36 Y. Q. Li, N. Hirosaki, R. J. Xie, T. Takeda and M. Mitomo, Chem. Mater., 2008, 20, 6704-6714.

37 J. Brgoch, C. K. H. Borg, K. A. Denault, A. Mikhailovsky, S. P. DenBaars and R. Seshadri, Inorg. Chem., 2013, 52, 8010-8016.

38 M. Grinberg, J. Barzowska, Y. R. Shen, R. S. Meltzer and K. L. Bray, Phys. Rev. B: Condens. Matter Mater. Phys., 2004, 69, 205101.

39 J. Gracia, L. Seijo, Z. Barandiarán, D. Curulla, H. Niemansverdriet and W. van Gennip, J. Lumin., 2008, 128, 1248-1254.

40 Y.-C. Lin, M. Bettinelli and M. Karlsson, Chem. Mater., DOI: 10.1021/acs.chemmater.8b05300.

41 Y. H. Kim, P. Arunkumar, B. Y. Kim, S. Unithrattil, E. Kim, S.-H. Moon, J. Y. Hyun, K. H. Kim, D. Lee, J.-S. Lee and W. B. Im, Nat. Mater., 2017, 16, 543-550.

42 J. Qiao, L. Ning, M. S. Molokeev, Y.-C. Chuang, Q. Liu and Z. Xia, J. Am. Chem. Soc., 2018, 140, 9730-9736.

43 B. Henderson and G. Imbusch, Optical Spectroscopy of Inorganic Solids, Clarendon Press, Oxford, 2006.

44 A. Allred, J. Inorg. Nucl. Chem., 1961, 17, 215-221.

45 S. J. Marin, M. O'Keeffe, V. G. Young and R. B. V. Dreele, J. Solid State Chem., 1991, 91, 173-175.

46 A. Nakatsuka, A. Yoshiasa and T. Yamanaka, Acta Crystallogr., Sect. B: Struct. Sci., 1999, 55, 266-272.

47 L. Seijo and Z. Barandiarán, Opt. Mater., 2013, 35, 1932-1940.

48 K. Nakamoto, Infrared and Raman Spectra of Inorganic and Coordination Compounds, Theory and Applications in Inorganic Chemistry, Wiley, 2008. 